BMJ

Open

Gastroenterology

\section{Impact of early cholecystectomy on the readmission rate in patients with acute gallstone cholangitis: a retrospective single-centre study}

To cite: Hoilat GJ, Hoilat JN, Abu-Zaid A, et al. Impact of early cholecystectomy on the readmission rate in patients with acute gallstone cholangitis: a retrospective single-centre study. BMJ Open Gastro 2021;8:e000705. doi:10.1136/ bmjgast-2021-000705

Received 9 May 2021 Accepted 18 July 2021

Check for updates

\section{(c) Author(s) (or their} employer(s)) 2021. Re-use permitted under CC BY-NC. No commercial re-use. See rights and permissions. Published by BMJ.

${ }^{1}$ Internal Medicine, SUNY Upstate Medical University, Syracuse, New York, USA ${ }^{2}$ Internal Medicine, Loyola University Medical Center, Maywood, Illinois, USA ${ }^{3}$ Department of Pharmacology, The University of Tennessee Health Science Center, Memphis, Tennessee, USA ${ }^{4}$ Department of Medicine, SUNY Upstate Medical University, Syracuse, New York, USA ${ }^{5}$ Gastroenterology, SUNY Upstate Medical University, Syracuse, New York, USA ${ }^{6}$ Gastroenterology, Syracuse VA Medical Center, Syracuse, New York, USA

Correspondence to Dr Gilles Jadd Hoilat; hoilatg@upstate.edu

\section{ABSTRACT}

Background and aims The pathogenesis of acute cholangitis (AC) occurs with biliary obstruction followed by bacterial growth in the bile duct. The leading cause of $\mathrm{AC}$ is obstructing gallstones. There have been conflicting theories about the optimal timing for cholecystectomy following AC. The aim of this study is to assess the impact of early cholecystectomy on the 30 -day readmission rate, 30-day mortality, 90-day readmission rate and the length of hospital stay.

Methods This retrospective study was performed between January 2015 and January 2021 in a highvolume tertiary referral teaching hospital. Included patients were 18 years or older with a definitive diagnosis of acute gallstone cholangitis who underwent endoscopic retrograde cholangiopancreatography (ERCP) with complete clearance of the bile duct as an index procedure. We divided the patients into two groups: patients who underwent ERCP alone and those who underwent ERCP with laparoscopic cholecystectomy (LC) on the same admission (ERCP $+\mathrm{LC})$. Data were extracted from electronic medical records. The primary endpoint of the study was the 30-day readmission rate.

Results A total of 114 patients with AC met the inclusion criteria of the study. The ERCP $+\mathrm{LC}$ group had significantly lower rates of 30 -day readmission $(2.2 \%$ vs $42.6 \%$, $\mathrm{p}<0.001)$, 90-day readmission ( $2.2 \%$ vs $30.9 \%, \mathrm{p}<0.001)$ and 30 -day mortality $(2.2 \%$ vs $16.2 \%, p=0.017)$ when compared with the ERCP group. In a multivariate logistic regression analysis, patients in the ERCP $+\mathrm{LC}$ group had $90 \%$ lower odds of 30-day readmission compared with patients who did not undergo LC during admission ( $0 R=0.1,95 \% \mathrm{Cl}(0.032$ to 0.313$), p<0.001)$.

Conclusion Performing LC on same day admission was associated with a decrease in 30-day and 90-day readmission rate as well as 30 -day mortality.

\section{INTRODUCTION}

Acute cholangitis (AC) is a systemic condition that occurs secondary to an infection and inflammation of the biliary tree. The pathogenesis of AC occurs with biliary obstruction followed by bacterial growth in the bile

\section{Summary box}

What is already known about this subject?

- According to the updated Tokyo Guidelines, initial management of acute cholangitis includes intravenous fluid resuscitation and appropriate antibiotic coverage followed by biliary drainage and subsequent cholecystectomy however the timing of the cholecystectomy is not defined and remains uncertain.

What are the new findings?

- The study shows that patients that underwent cholecystectomy on the same admission were found to have lower 30-day and 90-day readmission rates, a lower 30-day mortality rate as well as a reduced recurrence of biliary symptoms.

How might it impact on clinical practice in the foreseeable future?

- This study shows that performing early cholecystectomy is associated with better outcomes in patient with acute gallstone cholangitis and therefore, early cholecystectomy should be recommended following complete endoscopic clearance of the common bile duct.

duct. The leading cause of AC is obstructing gallstones.

AC is associated with significant morbidity and mortality if not addressed promptly with the main cause of death being multiorgan failure and irreversible shock. Hence, early recognition and risk stratification are crucial to guide further management. According to the updated Tokyo Guidelines, initial management of AC includes intravenous fluid resuscitation and appropriate antibiotic coverage followed by biliary drainage and subsequent definitive management of the primary aetiology. Biliary drainage can be achieved by several different procedures. Endoscopic retrograde cholangiopancreatography 
(ERCP) plays a key role in the management of AC and is the procedure of choice to extract the biliary stones. The endoscopic approach is preferred over the percutaneous transhepatic and the open drainage approach due to lower complication rates and shorter duration of hospitalisation. ${ }^{1-3}$

It has been shown that following clearance of choledocholithiasis, laparoscopic cholecystectomy (LC) reduces the incidence of recurrent biliary events. Therefore, it is now recommended that all patients with $\mathrm{AC}$ and gallstones undergo LC following biliary drainage. ${ }^{1}$

There have been conflicting theories about the optimal timing for cholecystectomy following AC. The aim of this study is to assess the impact of early cholecystectomy on the 30-day readmission rate, 30-day mortality, 90-day readmission rate and the length of hospital stay

\section{METHODS}

\section{Study design and population}

This retrospective study of patients with AC was performed in a high-volume tertiary referral teaching hospital at Upstate University Hospital in Syracuse, New York, USA between January 2015 and January 2021.

We only included patients that were 18 years or older with a definite diagnosis of acute gallstone cholangitis per the Tokyo guidelines 2018, who underwent ERCP with complete clearance of the bile duct as an index procedure.

We used the following search strategies: "acute cholangitis and ERCP", "acute obstructive cholangitis and ERCP", "acute cholangitis due to common bile duct stone and ERCP", "calculus of the common bile duct with

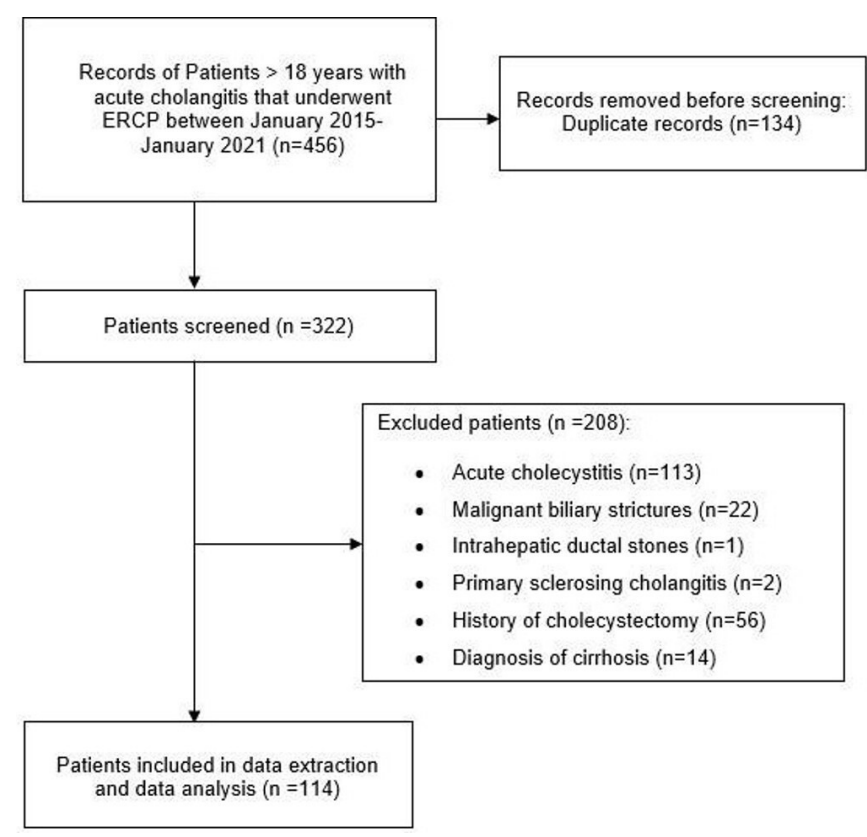

Figure 1 Flow diagram depicting the inclusion and exclusion criteria. ERCP, endoscopic retrograde cholangiopancreatography. acute cholangitis and ERCP”. We identified a total of 456 patients (figure 1) out of which 134 were duplicates.

Our exclusion criteria included patients with acute cholecystitis (113 patients), patients with malignant biliary strictures (22 patients), patient with intrahepatic ductal stones (1 patient), patients with primary sclerosing cholangitis (2 patients), patients with a history of cholecystectomy (56 patients) and patients with a diagnosis of cirrhosis (14 patients).

A total of 114 patients with $\mathrm{AC}$ met the inclusion criteria of the study.

\section{Data collection and outcomes}

A comprehensive chart review was conducted, and data were extracted from electronic medical records. Data included patient's age, gender, comorbidities, signs and symptoms and laboratory tests necessary to calculate the Tokyo score, Tokyo score, American Society of Anesthesiologist (ASA) score and ERCP notes. The primary endpoint of the study was the 30-day readmission rate. Secondary endpoints were the 90-day readmission rate, the cause of readmissions, the 30-day mortality rate and the length of hospital stay. If ERCP and LC were done on the same admission in ERCP +LC, then the length of hospital stay was considered as the length in one admission. On the other hand, the length of hospital stay in the ERCP group was the length it took from admission for ERCP till discharge (without regard to the LC).

\section{Data analysis}

Descriptive data were reported as numbers and frequencies, whereas continuous data were reported as means and SD. During admission, patients were divided into two arms: patient that only underwent ERCP on admission (ERCP group) and patients who underwent ERCP and LC during their index admission (ERCP+LC group). Univariate analyses for categorical and continuous data were performed using the $\chi^{2}$ and Student's t tests, respectively. A multivariate logistic regression analysis was carried out to detect the main factors associated with 30-day readmission rate. According to the univariate analysis results, only the statistically significant factors were included in the multivariate analysis model. All statistical analyses were two-sided and a $\mathrm{p}<0.05$ was regarded statistically significant. All statistical analyses were performed using the Statistical Package for Social Sciences (SPSS), V.24.0 for Windows.

\section{RESULTS}

A total of 114 patients with AC met the inclusion criteria of the study; 68 and 46 patients received ERCP and ERCP $+\mathrm{LC}$, respectively. Table 1 depicts the baseline characteristics of the included patients.

Overall, the gender of patients was equally distributed and the mean age $\pm \mathrm{SD}$ was $64.36 \pm 20.20$ years. The three most common comorbidities included hypertension $(55.3 \%)$, coronary artery disease $(28.1 \%)$ and chronic kidney disease $(23.7 \%)$. On the other hand, the three 
Table 1 Baseline characteristics of the patients $(n=114)$

\begin{tabular}{|c|c|c|c|c|}
\hline & $\begin{array}{l}\text { All patients } \\
\mathrm{n}(\%)\end{array}$ & $\begin{array}{l}\text { ERCP+LC } \\
\text { n (\%) }\end{array}$ & $\begin{array}{l}\text { ERCP } \\
\mathrm{n}(\%)\end{array}$ & P value ${ }^{\star}$ \\
\hline Overall sample size & 114 & 46 & 68 & \\
\hline Age in years - mean $\pm S D$ & $64.36 \pm 20.20$ & $63.31 \pm 22.58$ & $65.06 \pm 18.58$ & 0.655 \\
\hline Gender & & & & 0.170 \\
\hline Male & $58(50.9)$ & $27(58.7)$ & $31(45.6)$ & \\
\hline Female & $56(49.1)$ & $19(41.3)$ & $37(54.4)$ & \\
\hline \multicolumn{5}{|l|}{ Comorbidities } \\
\hline Hypertension & $63(55.3)$ & $26(56.5)$ & $37(54.4)$ & 0.824 \\
\hline Coronary artery disease & $32(28.1)$ & $14(30.4)$ & $18(26.5)$ & 0.644 \\
\hline Heart failure & $23(20.0)$ & $8(17.4)$ & $15(22.1)$ & 0.542 \\
\hline Diabetes mellitus & $27(23.7)$ & 5 (10.9) & $22(32.4)$ & 0.005 \\
\hline Chronic obstructive pulmonary disease & $19(16.7)$ & $4(8.7)$ & $15(22.1)$ & 0.060 \\
\hline Chronic kidney disease & $27(23.7)$ & $4(8.7)$ & $23(33.8)$ & 0.002 \\
\hline \multicolumn{5}{|l|}{ Signs and symptoms } \\
\hline Abdominal pain & $96(84.2)$ & $37(80.4)$ & $59(86.8)$ & 0.382 \\
\hline Fever, $>39^{\circ} \mathrm{C}$ & $28(24.6)$ & $5(10.9)$ & $23(33.8)$ & 0.005 \\
\hline Altered mental status & $26(22.8)$ & $11(23.9)$ & $15(22.1)$ & 0.817 \\
\hline Respiratory failure & $28(24.6)$ & $12(26.1)$ & $16(23.5)$ & 0.756 \\
\hline Vasopressor requirements & $24(21.1)$ & $10(21.4)$ & $14(20.6)$ & 0.882 \\
\hline \multicolumn{5}{|l|}{ Laboratory tests } \\
\hline Renal dysfunction (Cr >2 mg/dL) & $22(19.3)$ & $8(17.4)$ & $14(20.3)$ & 0.671 \\
\hline International normalised ratio $>1.5$ & $27(23.7)$ & $8(17.4)$ & $19(27.9)$ & 0.194 \\
\hline Platelets $<150 \times 103 / \mu \mathrm{L}$ or $>400 \times 103 / \mu \mathrm{L}$ & $18(15.8)$ & $9(19.6)$ & $9(13.2)$ & 0.363 \\
\hline WBC count $<4 \times 109 / \mathrm{L}$ or $>12 \times 109 / \mathrm{L}$ & $79(69.3)$ & $27(58.7)$ & $52(765)$ & 0.044 \\
\hline Albumin $<2.4 \mathrm{mg} / \mathrm{dL}$ & $23(20.3)$ & $10(21.7)$ & $13(19.1)$ & 0.732 \\
\hline Total bilirubin $(\mathrm{mg} / \mathrm{dL})-$ mean $\pm \mathrm{SD}$ & $3.62 \pm 1.81$ & $3.42 \pm 1.54$ & $3.76 \pm 1.97$ & 0.339 \\
\hline American Society of Anesthesiologists score & & & & 0.704 \\
\hline 1 & $8(7)$ & $4(8.7)$ & $4(5.9)$ & \\
\hline II & $22(19.3)$ & $11(23.9)$ & $11(16.2)$ & \\
\hline III & $58(50.9)$ & $22(47.8)$ & $36(52.9)$ & \\
\hline IV & $25(21.9)$ & $9(19.6)$ & $16(23.5)$ & \\
\hline V & $1(0.9)$ & $0(0)$ & $1(1.5)$ & \\
\hline Tokyo score & & & & 0.528 \\
\hline 1 & $33(28.9)$ & $16(34.8)$ & $17(25)$ & \\
\hline II & $27(23.7)$ & $10(21.7)$ & $17(25)$ & \\
\hline III & $54(47.4)$ & $20(43.5)$ & $34(50)$ & \\
\hline Common bile duct (CBD) stent inserted & $66(57.9)$ & $24(52.2)$ & $42(61.8)$ & 0.339 \\
\hline Admission to ERCP in days - mean $\pm S D$ & $1.63 \pm 1.55$ & $1.09 \pm 0.29$ & $1.21 \pm 0.41$ & 0.089 \\
\hline Admission to LC for $E R C P+L C$ group - mean $\pm S D$ & & $2.74 \pm 1.36$ & & \\
\hline \multicolumn{5}{|l|}{ LC after discharge for the control ERCP group } \\
\hline Within 30 days & & & $3(4.4)$ & \\
\hline Within 90 days & & & $9(13.2)$ & \\
\hline Within 120 days & & & $17(25)$ & \\
\hline Not performed within 120 days & & & $39(57.4)$ & \\
\hline
\end{tabular}

*Student's t-test for continuous variables and $\chi^{2}$ test for categorical variables.

ERCP, endoscopic retrograde cholangiopancreatography; $\mathrm{FiO}_{2}$, The fraction of inspired oxygen; LC, laparoscopic cholecystectomy; $\mathrm{PaO}_{2}$, the partial pressure of oxygen; WBC, white blood cell. 
Table 2 Main efficacy endpoints of the study

\begin{tabular}{|c|c|c|c|c|}
\hline & $\begin{array}{l}\text { All patients } \\
\text { n (\%) }\end{array}$ & $\begin{array}{l}\text { ERCP+LC } \\
\text { n (\%) }\end{array}$ & $\begin{array}{l}\text { ERCP } \\
\text { n (\%) }\end{array}$ & P value \\
\hline Overall sample size & 114 & 46 & 68 & \\
\hline 30-day readmission & $30(26.3)$ & $1(2.2)$ & $29(42.6)$ & $<0.001$ \\
\hline 90-day readmission & $22(19.3)$ & $1(2.2)$ & $21(30.9)$ & $<0.001$ \\
\hline Cause of readmission (biliary) & $49(42.9)$ & $2(4.3)$ & $47(69.1)$ & 0.771 \\
\hline 30-day mortality & $12(10.5)$ & $1(2.2)$ & $11(16.2)$ & 0.017 \\
\hline Cause of mortality (biliary) & $5(4.4)$ & $1(2.2)$ & $4(5.9)$ & 0.22 \\
\hline Length of stay in days - mean $\pm S D$ & $6.95 \pm 9.45$ & $5.54 \pm 2.91$ & $7.90 \pm 11.95$ & 0.193 \\
\hline
\end{tabular}

*Student's t-test for continuous variables and $\chi^{2}$ test for categorical variables.

ERCP, endoscopic retrograde cholangiopancreatography; LC, laparoscopic cholecystectomy.;

most common signs/symptoms included abdominal pain $(84.2 \%)$, fever $(24.6 \%)$ and respiratory failure $(24.6 \%)$. With regard to laboratory tests, the three most common findings included abnormal WBC counts (69.3\%), deranged international normalised ratio $(23.7 \%)$ and low serum albumin levels (20.3\%). Most patients had ASA score $\leq 3(77.2 \%)$. Roughly half of the patients had Tokyo score of III (47.4\%). Overall, the baseline characteristics did not differ significantly between both groups, except for diabetes mellitus $(\mathrm{p}=0.005)$, chronic kidney disease $(p=0.002)$, fever $(p=0.005)$ and abnormal WBC count $(p=0.044)$. The mean duration of admission to ERCP was 1.63 days $(\mathrm{SD}=1.55)$ without statistically significant difference between both groups. For ERCP $+\mathrm{LC}$ group, the mean duration of admission to LC was 2.74 days $(\mathrm{SD}=1.36)$. Only 6 patients $(13 \%)$ from the ERCP +LC had conversion to open cholecystectomy. For ERCP group, only 39 patients $(57.4 \%)$ did not undergo LC after ERCP.

With respect to the major outcomes of the study (table 2), the ERCP +LC group had significantly lower rates of 30 -day readmission $(2.2 \%$ vs $42.6 \%, \mathrm{p}<0.001)$, 90-day readmission $(2.2 \%$ vs $30.9 \%, \mathrm{p}<0.001)$ and 30 -day mortality $(2.2 \%$ vs $16.2 \%, \mathrm{p}=0.017)$ when compared with the ERCP group. The vast majority cause of readmission was biliary in both groups $(69.1 \%$ and $4.3 \%$ in the ERCP and ERCP + LC groups, respectively). Although the length of hospital stay was lower in the ERCP + LC group (5.54 \pm 2.91 days) when compared with the ERCP group ( $7.90 \pm 11.95$ days), however the mean difference was not statistically significantly different (mean difference $=-2.354$ days, $95 \%$ CI -5.918 to $1.21, \mathrm{p}=0.193$ ).

Table 3 displays a multivariate logistic regression analysis of 30-day readmission. Performing LC during admission along with ERCP was a statistically significant independent factor for 30-day readmission after adjusting for all potential factors. Specifically, patients who underwent LC during admission along with ERCP had 90\% lower odds of 30-day readmission compared with patients who did not undergo LC during admission $(\mathrm{OR}=0.1,95 \%$ CI 0.032 to $0.313, \mathrm{p}<0.001$ ) (table 3 ). Additionally, patients with fever on admission had $310 \%$ higher odds of 30-day readmission compared with patients who did not have a fever on admission (OR=4.105, 95\% CI 1.437 to 11.724 , $\mathrm{p}<0.001$ ) (table 3). Other factors that were statistically significant in the univariate analysis were not significant independent factors for 30-day readmission.

\section{DISCUSSION}

Theories regarding optimal timing for early cholecystectomy after an episode of AC remains debatable. Proportions of early cholecystectomy in patients with AC ranges from $28.6 \%$ to $37.2 \% .{ }^{45}$ Our study revealed that performing LC on index admission following complete endoscopic clearance of bile duct in patients with acute gallstone cholangitis significantly decreased the 30 -day readmission rate by $40.43 \%$ (absolute reduction rate). Furthermore, the odds of 30-day readmission rate was $90 \%$ less in the group of patients that underwent LC on the same admission.

The 90 -day readmission rate was decreased by $28.63 \%$ and the 30 -day mortality rate by $14 \%$ in patients that underwent concomitant ERCP and LC compared with patients that underwent ERCP alone. Although not statically significant, there was a total of 12 patients

\begin{tabular}{|c|c|c|c|}
\hline & OR & $95 \% \mathrm{Cl}$ & $P$ value \\
\hline $\begin{array}{l}\text { Diabetes mellitus } \\
\text { (ref: no) }\end{array}$ & 1.427 & 0.385 to 5.286 & 0.595 \\
\hline $\begin{array}{l}\text { Chronic kidney } \\
\text { disease (ref: no) }\end{array}$ & 1.159 & 0.336 to 3.999 & 0.816 \\
\hline $\begin{array}{l}\text { Abnormal WBC } \\
\text { count (ref: no) }\end{array}$ & 0.265 & 0.077 to 0.918 & 0.036 \\
\hline Fever (ref: no) & 4.105 & 1.437 to 11.724 & 0.008 \\
\hline $\begin{array}{l}\text { Laparoscopic } \\
\text { cholecystectomy } \\
\text { done on admission } \\
\text { (ref: no) }\end{array}$ & 0.1 & 0.032 to 0.313 & $<0.001$ \\
\hline
\end{tabular}

Ref, reference. 
who died, 11 of them belonging to the ERCP group. However out of these 11, only 5 patients expired from complications related to biliary causes. Nevertheless, early surgical intervention is associated with not only less morbidity but less mortality as well.

Delaying cholecystectomy or discharging patients without cholecystectomy was shown to be associated with a high risk of development of recurrent biliary pathologies close to $25 \% .{ }^{6}$ Indeed, Poon et at $t^{6}$ reported a $25 \%$ rate of recurring biliary concerns at 24 months in patients who did not have LC after an episode of cholangitis. Moreover, Schiphorst et al reported a 20\% recurrence rate of biliary symptoms as early as 22 days. ${ }^{7}$

Our study has showed that the 30-day cause of readmission was biliary in nature in $69.1 \%$ of the patients that underwent ERCP alone compared with $4.3 \%$ in the ERCP +LC group. Biliary causes were defined by any disease process related to the hepatobiliary system including but not limited to biliary colic, acute cholecystitis, AC, gallstone pancreatitis. This translates to an absolute reduction rate of $64.3 \%$. This was consistent with previous studies ${ }^{6-10}$ that showed that early cholecystectomy was associated with a reduced risk of recurrent choledocholithiasis and gallstone associated pathologies.

In our study, although patients that underwent cholecystectomy on the same admission had less comorbidities, less laboratory values derangements, lower ASA and Tokyo score; performing LC during admission was found to be an independent factor for the 30-day readmission rate after adjusting for all potential factors. An Abnormal WBC as well as fever were also independent factors for the 30-day readmission rate. Furthermore, Patients in the ERCP +LC group underwent two procedures on the same admission, yet the length of hospital stay was almost 2 days shorter compared with the patients that underwent ERCP alone (5.54 \pm 2.91 days vs $7.90 \pm 11.95$ days, $p=0.193$ ), however the results were not statistically significant. Accordingly, performing LC on same day admission was associated with a decrease in 30-day, 90-day readmission rate and did not prolong hospital stay.

There has been some hesitancy to perform cholecystectomy in the early stages following an episode of AC due to concern for increased inflammation which might make the surgery more difficult and higher risk. For this reason, surgeons prefer to have the patient discharged and wait for a 'cool-down' period before performing the cholecystectomy. However, several recent studies have shown that performing early cholecystectomy was not associated with higher operative times, intraoperative and postoperative complications. In fact, there was a lower rate of complications when LC was performed early as well as a lesser conversion rate to open cholecystectomy. ${ }^{11-14}$ Thus, performing early cholecystectomy should be achievable and safe and will decrease the rate of recurrence of AC as well as other gallstone related pathologies.
Based on the evidence shown, early cholecystectomy in patients with AC following ERCP during the same admission was associated with a lower 30-day and 90-day readmission rate as well as a reduced recurrence of biliary symptoms without any increase in intraoperative, postoperative complications and length of hospital stay. Therefore, early cholecystectomy should be recommended following complete endoscopic clearance of the common bile duct. Randomised clinical trials with a bigger sample size should be conducted to confirm the benefits of cholecystectomy during admission.

Our study is not without limitations. First, due to the strict exclusion criteria that we applied, the findings of our study cannot be applied to patients presenting with concomitant cholecystitis or patients with cirrhosis, intrahepatic ductal stones, primary sclerosing cholangitis and malignant biliary strictures. These patients were excluded to tailor our results towards patients with acute obstructive gallstone cholangitis and to avoid any confounder in our study. Cirrhosis was excluded because it is listed as a relative contraindication for a cholecystectomy. Second, our study was limited to one tertiary referral centre indicating that our patients might have more comorbidities, profound laboratory derangement as well as more severe presentations compared with patients in community hospitals. However, comorbidities were not associated with a 30-day readmission rate in the multivariate analysis. Moreover, we did not examine the time duration between the ERCP and LC. Rather, we just reported whether LC was done on the on the same admission, within 30 days, 60 days or 120 days. Lastly, as a drawback of retrospective studies, the two groups were unevenly divided in numbers as well as for some important parameters, such as diabetes mellitus, chronic kidney disease and fever.

Contributors GJH: study conception and design, acquisition of data, statistical analysis, interpretation of data, drafting of the manuscript, critical revision of the manuscript for important intellectual content, and submission of the manuscript. JNH: data analysis, interpretation of data, drafting of the manuscript and critical revision of the manuscript for important intellectual content. AA-Z: acquisition of data, interpretation of data, statistical analysis, drafting of the manuscript, and critical revision of the manuscript for important intellectual content. JR: acquisition of data and drafting of the manuscript. JT: acquisition of data and drafting of the manuscript. AM, VS: drafting of the manuscript and critical revision of the manuscript for important intellectual content. CC: critical revision of the manuscript for important intellectual content. BS: critical revision of the manuscript for important intellectual content, statistical analysis, study supervision; he is also responsible for the overall work as a guarantor.

Funding The authors have not declared a specific grant for this research from any funding agency in the public, commercial or not-for-profit sectors.

Competing interests None declared.

Patient consent for publication Not required.

Ethics approval Ethical consideration Approval for this study was obtained from the Institutional Review Board at Upstate University Hospital prior to data collection (1701401-1). Patient privacy was protected throughout this study.

Provenance and peer review Not commissioned; externally peer reviewed.

Data availability statement Data are available upon reasonable request. Deidentified participant data. 
Open access This is an open access article distributed in accordance with the Creative Commons Attribution Non Commercial (CC BY-NC 4.0) license, which permits others to distribute, remix, adapt, build upon this work non-commercially, and license their derivative works on different terms, provided the original work is properly cited, appropriate credit is given, any changes made indicated, and the use is non-commercial. See: http://creativecommons.org/licenses/by-nc/4.0/.

ORCID iD

Gilles Jadd Hoilat http://orcid.org/0000-0003-4493-9629

\section{REFERENCES}

1 Kimura Y, Takada T, Kawarada Y, et al. Definitions, pathophysiology, and epidemiology of acute cholangitis and cholecystitis: Tokyo guidelines. J Hepatobiliary Pancreat Surg 2007;14:15-26.

2 Boerma D, Rauws EAJ, Keulemans YCA, et al. Wait-and-see policy or laparoscopic cholecystectomy after endoscopic sphincterotomy for bile-duct stones: a randomised trial. Lancet 2002;360:761-5.

3 Sawyer RG, Jones RS. Acute cholangitis. In: Cameron JL, ed. Current surgical therapy. 8th ed. New York: Elsevier, 2004: 407-10.

4 Li VKM, Yum JLK, Yeung YP. Optimal timing of elective laparoscopic cholecystectomy after acute cholangitis and subsequent clearance of choledocholithiasis. Am J Surg 2010;200:483-8.

5 Wang C-C, Tsai M-C, Wang Y-T, et al. Role of cholecystectomy in choledocholithiasis patients underwent endoscopic retrograde cholangiopancreatography. Sci Rep 2019;9:2168.
6 Poon RT, Liu CL, Lo CM, et al. Management of gallstone cholangitis in the era of laparoscopic cholecystectomy. Arch Surg 2001;136:11-16.

7 Schiphorst AHW, Besselink MGH, Boerma D, et al. Timing of cholecystectomy after endoscopic sphincterotomy for common bile duct stones. Surg Endosc 2008;22:2046-50.

8 Alsayid M, Awadalla M, Albo B, et al. The impact of laparoscopic cholecystectomy on 30-day readmission rate for acute cholangitis patients: a single-center study. Dig Dis Sci 2021;66:861-5.

9 Elmunzer JB, Noureldin M, Morgan KA, et al. The impact of cholecystectomy after endoscopic sphincterotomy for complicated gallstone disease. Am J Gastroenterol 2017;112:1596-602.

10 Sarli L, lusco D, Sgobba G, et al. Gallstone cholangitis: a 10-year experience of combined endoscopic and laparoscopic treatment. Surg Endosc 2002;16:975-80.

11 Friis C, Rothman JP, Burcharth J, et al. Optimal timing for laparoscopic cholecystectomy after endoscopic retrograde cholangiopancreatography: a systematic review. Scand J Surg 2018;107:99-106.

12 Trejo-Ávila M, Solórzano-Vicuña D, García-Corral R, et al. Laparoscopic cholecystectomy after endoscopic treatment of choledocholithiasis: a retrospective comparative study. Updates Surg 2019;71:669-75.

13 Discolo A, Reiter S, French B, et al. Outcomes following early versus delayed cholecystectomy performed for acute cholangitis. Surg Endosc 2020;34:3204-10.

14 Abe T, Amano H, Hanada K, et al. Efficacy and safety of early cholecystectomy for comorbid acute cholecystitis and acute cholangitis: retrospective cohort study. Ann Med Surg 2019;38:8-12. 